\title{
A NATUREZA DA LINGUAGEM ESCRITA EM CONTRASTE COM A LINGUAGEM FALADA
}

\author{
David Shepherd \\ Universidade Federal do Paraná
}

\begin{abstract}
RESUMO
O objetivo deste estudo é explorar a natureza da escrita do ponto de vista lingüistico em termos bem acessíveis para o aluno de pósgraduação sem experiência no campo. Assim o estudo é uma visão geral de várias autoridades lingüisticas cujas publicações incluem descrições sobre a linguagem escrita em contraste com a falada. Há então alguns aspectos sobre a linguagem escrita como substância, a linguagem escrita como uma operação, a aquisição da escrita, além do ângulo sociolingüistico i. é, a linguagem escrita em termos das funções comunicativas e da percepção da audiência.
\end{abstract}

\section{INTRODUÇĀO}

O objetivo deste ensaio é explorar a natureza da escrita. ${ }^{1}$ Isto advém de minha insatisfação com a negligência relativa dos lingüistias com a linguagem escrita porque ela é ontogeneticamente (em indivíduos) e filogenicamente (na história humana) secundária à fala. ${ }^{2}$ A escrita tem

\footnotetext{
${ }^{1}$ Neste estudo os termos escrita e linguagem escrita são usados sem se fazer distinção entre eles. Há uma tendéncia nas obras teóricas em inglés de se estabelecer que escrita é essencialmente um ato físico, enquanto que a linguagem escrita é um produto. Desta forma, o paralelo e feito algumas vezes entre a disferença competència/"performance" na linguagem oral. A sugetảo é que enquanto se pode ter a capacidade (competència) para a linguagem escrita, a composição, seleção de palavras e idéias, um defeito f/sico poderá restringir o ato motor da eserita ("performance"l, a transcrição, o esforço físico e a legibilidade.

${ }^{2}$ Que é cronologicamente precedente é diretamente e instrumentalmente envolvida na aquisição da primeira língua de uma pessoa.
} 
sido considerada menos persuasiva, menos estruturalmente completa. Não pode haver dúvida quanto à aceitação que a fala veio antes da escrita ou que a escrita como representação é um código lingüístico que seque o oral tanto no desenvolvimento como na estrutura. O homem á acima de tudo um animal que fala, para quem a fala é fundamental.

Eu também não ousaria desafiar lingüistas que corretamente aceitam "The principle of priority of the spoken language over the written. . . (because) . . . no writing system represents all the significant variation of pitch and stress which are present in spoken languages". ${ }^{3}$

Isto tem implicado, entretanto, uma hierarquia de valores em que a escrita, sendo derivativa, é de algum modo inferior. Enquanto se aceita a preocupação dos lingü ístas em colocar a fala no seu devido lugar depois de muitos séculos de negligência, pode-se debater a sugestão. de Bloomfield 4 de que "writing is merely a device for recording speech". E meu objetivo neste estudo argumentar que a língua tem 2 modos, ${ }^{5}$ a fala e a escrita, que são variáveis, paralelos mas não permutáveis meios de expressão contrastivos. (Uma metáfora possivel para a relação entre "fala e escrita" pode ser feita em termos de dois tipos de rodovia a "via rápida' e a 'via expressa' em Curitiba, com bases e direções paralelas mas funcionando para diferentes tipos de transportel.

A escrita atingiu um certo prestígio e reconsideração durante a última década, marcada por interesse em competência comunicativa ${ }^{6}$, por enfoques funcionais ${ }^{7}$. Entretanto creio que uma revaliação seja devida em nível pedagógico e que um estudo mais minucioso dos mecanismos, do "imput" lingüistico e das funções lingüisticas pertinentes à escrita poderia perfeitamente fornecer detalhes relevantes ao ensino da leitura, também.

E óbvio que este estudo não inclui dois aspectos cruciais para um entendimento lingü ístico das diferenças entre a linguagem falada e escrita: uma análise contrastiva da estrutura textual como da estrutura do discurso. Estes dois aspectos serão os tópicos de dois estudos mais amplos a serem feitos pelo autor numa data futura.

${ }^{3}$ LYONS, J. Introduction to theoretical linguistics. 2. ec. Cambridge. Cambridge University Press. 1972. p. 38.40.

${ }^{4}$ BLOOMFIELD, L. \& BARNHARDT, C. L Let's read: a linguistic approach. Detroit, Wiley 1961 . p. 75.

5 Parece haver um grau considerável de confusāo na literatura sobre linguistica quanto ao uso da palaura "mode" em inglès. Aqui "modo" é visto como substancia ous representaçāo (ABERCROMBIE. D. Elements of general phonetics. Edinburgh, Edinburgh University Press. 1971. p. 5.) e näo como um código ou mensagem como é assim descrito por CRYSTAL. D. \& DAVY, D. Investigeting English style. London. Longman, 1969. p. 68.

${ }^{6}$ HYMES, D. Toward ethnographies of communication: the analysis of communicative events. In: GIGLIOLI. P. P., ed. Language and social content. Harmondsworth. Penguin, 1972. p. 27.

7JAKOBSON, R. Concluding statement: linguistics and poetics. In: SEBEOK, T. A., ed. Styla in langusag. Cambridge. Mass., MIT Press, 1971. p. 350. 


\section{A ESCRITA E A FALA COMO SUBSTÃNCIAS}

Tanto a escrita como a fala deveriam ser vistas como veículos ou meios, tendo um valor extrínseco como parte de um sistema de linguagem. Assim, os mercadores concretos das formas plurais, por exemplo, na fala, podem ser entendidos sem referência à escrita e vice-versa. Saber uma lingua pode ser considerado como a habilidade de relacionar dois sistemas independentes e reconhecer que distinções de sons e símbolos gráficos correspondem à que distinções abstratas na mente. Os dois códigos poderiam ser perfeitamente considerados como "different substances having existence in the real world. . . and signifying abstract distinctions in the mind"8. E óbvio que essas duas substâncias diferem uma da outra em vários detalhes importantes:?

\section{Fala}

"Substância: distúrbio no ar produzida por: pulmões e órgãos da voz

percebida por: ouvidos

organizada: no tempo

produção: rápida, natural

instrumentos: não

permanente: não

transportável: não

\section{Escrita}

marcas no papel mãos, instrumentos

olhos

no espaço

vagarosa, laboriosa

sim

sim

sim"

E claro que, através deste diagrama, ${ }^{9}$ não é necessário haver nenhum elo entre os dois meios. Entretanto, nós professores estamos conscientes da relação direta e convencional entre a "fala do professor" e as "anotações do aluno", o que torna a transposição possivel.

A escrita é claramente baseada em símbolos que correspondem a unidades percebidas na língua falada mas que não precisam ser unidades de som. Nem todos os sistemas de escrita são alfabéticos, nem todos os sistemas alfabéticos, como o Português, relacionam a escrita a outras partes da estrutura da língua. Existem línguas silábicas, fonêmicas, além de alfabéticas. As últimas começaram com o sistema cirílico grego. $\mathrm{Na}$ escrita do Chinês, há unidades de significado, pictogramas e ideogramas onde a correspondência se dá entre o sinal (ou símbolo) e o objeto

${ }^{8}$ O'DONNELL, W. R. \& TODD, L. Variety in contemporary English. London, Allen \& Unwin, 1980. p. 4.

${ }^{9}$ O'DONNELL \& TODD. p. 5.

Letras, Curitiba (33) $145-162$ - 1984 - UFPR 
ou conceito no mundo exterior. ${ }^{10}$ Da mesma forma temos símbolos em Portuguçes: números, $1,2,3$, etc.

A escrita (ao contrário da fala) na nossa cultura tem sido olhada tradicionalmente como um isomorfo de primeira ordem em relação à linguagem oral por causa da correspondência grafema/fonema. (da mesma forma estenografia poderia também ser um isomorfo de primeira ordem, e o Sistema Braille e os códigos telegráficos isomorfos de segunda ordem ou de ordem maior). Entretanto, o ator motor de 'escrever (o desenho, o espaçamento, a direção e a seqüēncia) é muito mais do que uma simples correspondência grafema/morfema. A alegação de que símbolos gráficos para os fenômenos que não sejam letras, como a pontuação por exemplo, representando entonação, altura de voz, acentuação e função (elementos tais conhecidos como suprasegmentais) é também algo simplista. A escrita é a arte da produção ou codificação de símbolos na forma própria, com espaços próprios, na seqüência e direção próprias.

\section{A AQUISIÇĀO DA ESCRITA.}

A fala é adquirida numa idade tenra, inconsciente e naturalmente e sem dor. A escrita é para fala o que a algebra é para a aritmética; vem com a maturação, como uma abstração. Treina a mente nos sistemas artificiais de representação. O seu domínio requer um alto grau de abstração. E precisamente por isto que as crianças não conseguem identificar a escrita com suas próprias experiências. "It is the abstract quality of written language that is the main stumbling black. . . the motives fo writing are more abstract, more intellectualized". ${ }^{11}$

Esta qualidade abstrata da comunicação escrita é intensificada por seu deslocamento no tempo, por seu distanciamento, de traços expressivos e, frequentemente pela func.ão expressiva da fala tanto quanto pela falta de um contexto material.

A habilidade de se usar a escrita como um meio adicional de comunicação lingüistica ná língua mãe, para a criança ou o adulto, é aprendida através de um esforço consciente em resposta ao ensinamento. É uma atividade que vem em segundo lugar, a qual não surge naturalmente como uma conseqüência da interação com objetivos sociais, isto é, não é adquirida como conseqüência da atividade humana normal. Assim, a escrita é uma habilidade aprendida e não adquirida. ${ }^{12}$ Um grupo de palavras de importância especial para a linguagem

${ }^{10}$ VYGOTSKY, L. S. Thought and language. New York, Wiley, 1962. p. 99.

11 JAKOBSON, p. 361.

${ }^{12}$ KRASHEN, S. D. Second language acquisition and second language learning. Oxford, Pergamon Press, 1981. p. 19. 
escrita é aquele que marca relações lógicas entre proposições, palaurıs que combinam frases em textos, que existem de alguma forma na fali, mas são mais æssenciais à escrita. ${ }^{13} \quad 14$

Algumas medidas de complexidade lingüística utilizam estas conecções e marcam uma área de èrros frequentes na aquisição da primeira língua por parte da criança. No discurso escrito, conectivos entre proposições são necessários e são um dos aspectos que têm sido usados para separar a escrita da linguagem, de linguagem escrita nos primeiros anos escolares. ${ }^{15} \mathrm{De}$ acordo com Piaget ${ }^{16}$ vê-se o completo desenvolvimento da manipulação destas operações simbolicamente (isto é na linguagem somente) no "período operacional formal". O mesmo autor liga a sua ordem de surgimento com as operações cognitivas.

Além da representação, que é a forma, expressão ou meio da escrita, e sua relação isomórfica com a língua, os educadores precisam estudar o conteúdo/mensagem da forma escrita e sua representação do pensamento no escolar. O desenvolvimento da escrita na criança é uma mecânica junto com raciocínio e estes são justapostos e interelacionados.

\section{A ESCRITA COMO OPERAÇĀO.}

A escrita liberta as pessoas do conceito "aqui e agora", removendo a mesma atividade do tempo histórico e real; é por isso que ela tende em direção ao conservadorismo. Isto tem permitido, por outro lado, a maior liberdade de mudança lingüística para a linguagem falada. Esta liberdade, um controle extrínsico, permite aos escritores manipular o espaço e o tempo. Assim o leitor pode escolher, a opção de estudar um texto vagarosamente para comprendê-lo detalhadamente, pode apressar seu rítmo para tirar só os pontos principais, pode lê-lo superficialmente ou ainda lê-lo, omitindo pedaços relevantes de acordo com seu objetivo e motivação.

A motivação social é o fator que governa a escrita, de acordo com Leontiev ${ }^{17}$, para quem a escrita é uma atividade que tem um propósito pré-estabelecido como também um objetivo dinâmicu para assegurar a

${ }^{13}$ Estes elementos tếm vários nomes na literatura - retórica/discurso, identificadores/ conectivos e que serão abordados com maior detalhe em Estrutura do texto, do autor, no prelo.

${ }^{14} \mathrm{O}$ primeiro é simplesmente a fala escrita (como exemplo, transcriçōes de fitas gravadas). O último pode ser bascado em linguagem oral, mas inclui limites (como exemplo a coesão (HALLIDAY, M. A. K. \& HASAN, R. Cohesion in English. London, Longman, 1976. p. 328) que se aplica exclusivamente à linguagem escrital.

${ }_{15}^{15}$ WEINREICH, U. Languages in contact. 4. ed. The Hague, Mouton, 1966. p. 158.

${ }^{16}$ GINSBURG, H. \& OPPER, S. Piaget's theory of intellectual development: an introduction. Englewood Cliffs, Prentice-Hall, 1969. p. 258.

17 LEONTIEF, citado por MARKOVA, A. K. The tasching and mastery of languages. Lon. don, Croom Holm, 1979. p. 54.

Letras. Curitiba (33) 145-162 - 1984 - UFPR 
mais perfeita finalização. Esta motivação e este propósito determinarão o formato e a especificidade da escrita; a natureza da atividade determinará seu próprio desenvolvimento no qual tanto estruturas quanto funções se desenvolverão simultaneamente. A escrita no ponto de vista de Leontiev, não é simplesmente uma representação da língua escrita nem é simplesmente um meio alternativo de criação, mas uma alteração da cognição e psicologia do autor em questão.

Para Vygotsky, ${ }^{18}$ a escrita é uma extensão perceptual da linguagem falada; a última tem que ser procurada rapidamente devido à memória auditiva. Ela é unilinear e unidirecional. A escrita por outro lado é bidirecional e permanente, permitindo que a leitura de um texto se faça tanto para cima como para baixo, para frente ou para trás. (note-se o uso no discurso escrito de um conjunto cuidadosamente selecionado de elementos de referência que atuam anafórica e cataforicamente.) É portanto, multilinear. Estes aspectos capacitam a escrita a ajudar o planejamento e encorajam o pensamento deliberado e premeditado. A procura de expressōes apropriadas define pensamentos criativamente através do ato de codificar a idéia em palavras. Desta forma, no ponto de vista de $V$ ygotsky, a linguagem cria realidade e experiência; não é meramente uma representação. A extensão psicológica da mente como um instrumento muda todo o funcionamento cognitivo, e não somente a percepção como também a memória, a conceituação e a atenção. "The inclusion of a tool in the process of behaviour ... alters the course and individual features of all mental process. . ${ }^{19}$

Ao dirigir a atenção consciente, a escrita capacita a criança a "rise to a higher level of speech development". ${ }^{20}$ ao mesmo tempo que a conscientização dá controle à função. Assim, a escrita, para Vygotsky é a fala sem o interlocutor, baseando-se no "inner speech" para desenvolver seu pensamento e conteúdo. A descontextualização subsequente e progressiva da linguagem escrita em textualização é vista como a mais marcante caracteristica da forma escrita em contraste com a forma oral. De acordo com Vygotsky" esta textualização requer "deliberate structuring of the web of meaning. . . (which) relies on formal meanings ... syntactic differentiation is at a maximum".

Pode a linguagem ser dividida categoricamente entre fala verso escrita? Ocasionalmente a escrita é muito parecida com certas formas de fala; algumas vezes a linguagem falada não é totalmente diferente do jeito que escrevemos. Smith ${ }^{22}$ sugeriu que são as circunstâncias

\footnotetext{
18 VYGOTSKY, p. 117 .

19 VYGOTSKY, p. 1-4.

DVYGOTSKY, D. 10 .

21 VYGOTSKY. D. 100 .

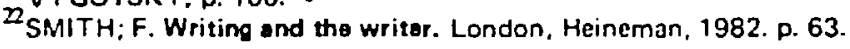


que definem e que uma importante distinção que torna sem efeito a divisão crua entre a "fala" e a "escrita", é a categorização de linguagem como "dependente da situação" por um lado e "dependente do contexto" por outro. No primeiro caso tanto a fala como a escrita são relacionados com o ambiente físico. Como conseqüência disto, o que se produz oralmente é frequentemente curto ou/e fragmentado: "café . . .?" . . . "tá." A linguagem suscinta e incompleta da palavra impressa ou sinais nas ruas, lojas, pacotes, portas e rótulos é diferente do texto e não permite elementos idiossincráticos.

$\mathrm{Na}$ segunda categoria ("dependente do contexto"), linguagem é determinada pelo contexto, isto é, se palavras fossem mudadas ou reorganizadas o texto não mais teria a mesma mensagem, ${ }^{23}$, particularmente na escrita onde há um texto físico que forma um todo maior que a soma de suas partes. A escolha da linguagem é crucial para a comunicação. Portanto ela não pode ser concisa, idiossincrática ou elítica. Tem que ser elaborada para facilitar a compreensão. (de um interlocutor ausente na escrita).

$E$ óbvio que a linguagem pode frequentemente ser uma mistura de ambas as categorias, dependentes de situação e contexto, sendo justapostas simultaneamente.

\section{AS FUNÇŌES DA ESCRITA;}

A escrita é funcionalmente independente da fala, ocupando uma área muito mais restrita do uso cotidiano da linguagem. Se a fala preenchesse todas as necessidades da comunicação, a escrita jamais teria existido. Sociedades primitivas não têm escrita; suas novas necessidades é que originaram o meio da escrita. O fato de que poucos de nós jamais atingimos um nivel satisfatório de expressividade na linguagem escrita é uma clara demonstração de que ela não é uma variação livre da fala, na qual a maioria de nós opera uma variedade mais ampla de funções, pois a fala é usada para transação e interação social. (Apesar de que, como Bernstein ${ }^{23}$ demonstrou, somente uma minoria possa atuar satisfatoriamente em todas essas funções). Dai também a falha dos alunos de áreas sócio-econômicas pobres em adquirir uma competência razoável ao lidar com o código escrito, pois eles representam somente um extremo das variedades da comunicação lingüistica. (classificado como "frozen" por Joos ${ }^{25}$ I. Nem as circunstâncias em que a linguagem

${ }^{23}$ CLARK, R. Adult theories, child strategies and their implications for the language teacher. In: ALLEN, J. P. B., CORDER, S. P. The Edinburgh course in applied linguistics. London, Oxford University Press, 1975. v. 2, p. 333 - 4.

${ }^{34}$ BERNSTEIN, B. Social structure, language and learning. Educational Research (3):16376. 1971.

2JJOOS, M. The five clocks. Wilmington, University of Indiana Press, 1962. p. 87.

Letras, Curitiba (33) 145.162 - 1984 - UFPR 
escrita opera, nem os papéis sociais da escrita são idênticos com a fala: o Davies apontou "writing is the activity of the minority, the professional people. . . who write in conformity with conventions which belong to their normal professional routines..."26

A escrita é a linguagem em sua forma editada, diferenciada da fala não somente pela mecânica imposta pela disposição das letras e pontuação mas por deliberação. É um objeto a ser contemplado e desenvolvido a gosto; dal a "minority" de Davies. Entretanto, com o crescimento da cultura, a linguagem elaborada provará ser, assim esperamos, menos uma característica de poucos e mais uma forma disseminada de comunicação.

Que situações requerem a linguagem escrita? Sempre que a pessoa a quem se dirige não é acessível do discurso direto há duas situações possíveis. A primeira ocorre quando o interlocutor está ausente. Este é o caso da correspondência pessoal quando o interlocutor não é conhecido, uma situação semelhante àquela da conversa telefônica e definida como "escrita pessoal" 27

A segunda é quando o interlocutor é desconhecido, uma situação que demanda a assim chamada comunicação "institucional". Esta comunicação é de certa forma menos complexa e variada que a primeira como convenção que governa as relações interpessoais. Foi sugerido que o papel essencial da linguagem escrita é como um fenômeno institucional. Pode ser alegado que a função social da cultura numa sociedade como a nossa é servir àquela instituições que são criadas para definir padrões de pensamento e comportamento. A escrita transmite influência e informação, é uma referência estável para leis e costumes; cria uma transcrição permanente de sabedoria acumulada e herança cultural. Popper ${ }^{28}$ definiu a escrita como uma atividade mediativa, um arquivo da capacidade intelectual que transcende as limitações da memória humana. Não há dúvida que uma das funções da linguagem escrita é fornecer transcrições exatas não só do que é dito, mas também do que é feito entre intelectuais, para o estabelecimento dos valores culturais e para a criatividade literária. As sociedades não cultas usam baladas, muito faladas, menestréis ou contadores de estórias. As culturas que possuem a linguagem escrita tendem a ter processos institucionalizados, especializados e educacionais cuja função é ensinar o código escrito e manter a aquisição da experiência, fora dos limites de nosso tempo e espaço individual, não disponivel à culturas puramente orais.

${ }^{26}$ DAVIES, A. \& WIDDOWSON. H. G. Reading and writing. In: ALLEN \& CORDER, v. 3, p. 163.

27 DAVIES \& WIDDOWSON, p. 166.

20POPPER, K. R. Objective knowledge. Oxford, Clarendon Press, 1972. p. 107. 
Ao fornecer um registro permanente, é claramente uma fonte de referência posterior tanto quanto uma evidência física de consecução, que é a razão pela qual, na maioria das sociedades que tem ambas as formas de linguagem, é usada para propósitos contratuais, acordos, regulamentações e leis. Como Bolinger ${ }^{29}$ já disse "by freeing speech from its helpless dependence on memory, visual symbols (writing) conferred on language a completeness and elaboration which were not possible before".

Ao ser capaz de se separar de suas idéias, de um modo impossivel com linguagem transiente, o pular sua mensagem. Como o produtor e o receptador tem um controle intrínsico do tempo e espaço, podem decidir sobre o rítmo.

Tanto a fala quanto a escrita são caracterizadas pelas três seguintes áreas de função ampla: a primeira poderia ser chamada "interacional" e inclui: pedidos, fornecimentos de informações, recusas, sugestões, contradições, etc, à segunda é a "referencial", que em termos, inclui três tipos de função principais: instrução, narração e descrição. Muito da referência na fala se relaciona com os antecedentes da situação e requer referência menos explícita. Estas três últimas funções são característicamente associadas pelos traços do código: imperativo, passado simples e presente simples em prosa acadêmica. A terceira área é "atitudinal", a qual incluiria comentários, avaliação, comparação, planejamento, etc. E claro que as duas últimas são de fundamental importância na escrita.

Luria $^{30}$ enfantizou a função diretiva da língua, isto é, a sua habilidade, tanto como escrita como fala, de não só seguir ou acompanhar a ação de conduzir ou dirigí-la.

\section{A ESCRITA E O SENTIDO DE AUDIENNCIA.}

A escrita implica a codificação de uma mensagem e a tradução de pensamentos em forma gráfica; a leitura envolve a decodificação de uma mensagem visualmente e a interpretação dos pensamentos do autor las exceções seriam aquelas em que o escritor escreve para si próprio para uso posterior, como por exemplo; uma lista de compras, um diário, memorandos para o dia seguinte, planos de ataque, agendas para encontros, etc.)

Por outro lado, como já dissemos acima, a comunicação através de fala espontânea propicia um intercâmbio constante entre o emissor e o

${ }^{29}$ BOLINGER, D. Aspects of language. 2. ed. New York, Harcourt, Brace, Jovanovich, 1975. p. 163. 1959.

${ }^{30}$ LURIA. A. R. Development of the directive function in speech. Word, 15:341-52, 
que ouve, o que controla o que se diz, quando se diz e como é dito. Nos dirigimos a uma presença física e assim a intenção é alimentada por uma constante resposta de natureza lingüistica e não lingü ísti za. O receptor acusa recebimento das palavras numa variedade de modos incluindo murmúrios, perguntas, comentários e usando elementos paralingüísticos, principalmente expressões faciais para mostrar suas reações. Isto permite àquele que fala verificar suas presuposições sobre aquele que ouve e, estando sempre consciente de reações e atitudes, pode responder de acordo. Onde há uma sugestão de dificuldade, desacordo, falta de entendimento satisfatório ou intercâmbio de idéias, há convenções claras $^{31}$ para permitir "conversation take-overs". O falante numa interação face a face fica simultaneamente assegurando o sentido geral, planejando o futuro desenvolvimento do argumento enquanto monitora sua proxima fala. Esta é a razão pela qual a linguagem fala é mais repetitiva, chia de canalizadores e controle interativo ${ }^{32}$ e é geralmente mais rápida que a escrita. (Isto não quer dizer que a redundância não existe em escrita). A fala também contem conteúdo cognitivo mais difuso que a linguagem escrita. Assim a fala discursiva é fragmentária, elítica, não requer precisão e contem menos informação fatual que o discurso escrito ${ }^{33}$. O emissor tem uma variedade de caracteres prosódicos (rotulados de "voice dynamics" por Abercrombie ${ }^{34}$ a seu dispor, incluindo, altura de voz, amplitude, velocidade, ritmo e pausas. A mensagem é frequentemente passada não pelo que dizemos, mas por como dizemos e como nos parecemos quando o dizemos. O emissor só terá dificuldades sérias quando faz um sermão, discurso ou palestra enquanto a audiência pode estar relativamente passiva. As dificuldades também surgir no caso de conversas telefônicas, como já mencionamos anteriormente.

Em linguagem escrita o peso todo de comunicação cai sobre os elementos escritos mesmo. Ela não tem muitas das ajudas para comunicação extra-lingüística descritos acima, que o emissor utiliza com um interlocutor numa interação para a face. A escrita é um evento pessoal que ocorre em comparativo isolamento. A escrita propriamente dita é a atividade relevante em seu todo; o processo é isolado. Desta forma ele deve criar um ambiente novo com diferentes respostas para ele. $O$ contato com o leitor é feito através de simbolos gráficos abstratos somente, sem nenhum recurso a prosódia. A mensagem é apresentada exclusiva-

${ }^{31}$ SACHS, H. at alii. A simple systematics for the organisation of iurn-taking for conversation. Languege, $50(4): 1974$.

${ }^{32}$ SCHEGLOFF. E. A Notes in conversation practice: formulating palce. In: GIGLIOLI. P. P., ed. Langusgo and social context. Harmondsworth, Penguin, 1972. p. 98.

${ }^{3}$ URE, J. Loxical density and register differentiation. In: TRIM. J. M. L. ed. Application of linguistics; selected papers on the Second International Congress of Applied Linguistics. London. Cambridge University Press, 1971. p. 134.

${ }^{34}$ ABERCROMBIE, p. 89.91. 
mente em forma lingüística linear, escrita devagar, lida ao tempo do leitor, revisada e reescrita. Isto, é claro, justifica os hábitos de mastigar canetas, coçar a cabeça. Como a escrita é uma atividade solitária sem nenhuma resposta imediata, o autor não repetir, retraçar seus passos e expandir como o faz na fala. Ele tem que incorporar o papel de ambos os participantes de um diálogo. Apesar de o autor nunca estar completamente certo do grau de conhecimentos, idéias, atitudes e presuposições, ele deve tentar seriamente antecipar as dúvidas e possiveis perguntas do se interlocutor ausente. Ele mantém o canal aberto através de esforço, envolvendo escolha chidadosa da estrutura, elos e seqüência de idéias. Assim, o produto tem que ser apresentado no papel de tal forma que poderá comunicar (àquele com quem se fala) em isolamento. $O$ tex to tem que ser capaz de ter sua própria validade, a estrutura de superfície de carregar todas as nuances de significado transmitidas pela entonação, na fala. É claro, portanto, que "atos de comunicação feitos pela linguagem escrita não têm correspondentes exatos aqueles feitos pela linguagem oral". ${ }^{35}$

O cuidado e a precisão têm que compensar a falta de elementos paralingüisticos dos quais não se pode fazer uso na comunicação unilateral. Desta forma o texto tem que ser organizado num todo coerente, explícito e completo para fazer com que a mensagem seja interpretada pelo leitor do modo pretendido.

O escritor tem tempo para decisões deliberadas para criar consistência interna, editando ambiguidades e excluindo redundâncias, desta forma não se antagonicando com o leitor.

A escrita tem meios específicos de clarificação, isto é uma série de meios gráficos que incluem titulos, cabeçalhos, pontuação, letras maiúsculas (que em inglès indicam os substantivos próprios), parágrafos, sublinhação, disposição, uma variedade de tipologias e divisões de palavras (que distinguem ambiguidades de homófonos e genitivos, por exemplo).

Como a linguagem escrita é relativamente permanente e pode ser usada como referência posterior pelo leitor, a linguagem escolhida é muito frequentemente conservadora, "congelada," i. e. convencionalmente ampliada para atingir significado explícito (como exemplos temos: "com referência a". "no tocante a") ou pode incluir elementos redundantes da "contact function" (como "em inicialmente', 'em resumo', 'pode-se dizer'). E por isto que, na introdução de muitos artigos acadèmicos ou livros, começa-se por estabelecer o conteúdo, a limitação do assunto. Este uso da "função metalingüística"36 e uma ilustração da necessidade de o escritor identificar sua audiência e seus parâ-

${ }_{36}^{36}$ WIDDOWSON, H. G. Language and communication. Edinburgh. 1973. Mimeografado.

3 JAKOBSON, p. 359.

Letras, Curitiba (33) 145-162 - 1984 - UFPR 
metros estabelecendo então um teto ou nivel de conhecimento. $O$ uso de abstratos têm ao início de ensaios acadêmicos, uma função semelhante. Assim, somente uma das razões para a escrita (é a 'ala) é o desejo de comunicar idéias. Os propósitos mencionados acima incluem o estabelecimento e a manutenção de relacionamento com a pessoa a quem nos dirigimos. Um outro é a ordenação dos pensamentos do autor sobre um tópico em particular. E por isso que o escritor tem que usar uma grande variedade de particularidades lingüisticas (para suprir a ausência de um receptor ausente), para expressar seu ponto de vista ${ }^{37}$ ("modal function") explicar sua terminologia e sua compreensão de expressões e especificas de sua área ("função metalingüistica") e manter o canal aberto para contatar o leitor e desta forma reter controle sobre o "diálogo".

A escrita é portanto essencialmente interativa e poderíamos dizer que para uma comunicação eficiente em linguagem escrita o emissor tem que se fazer quatro perguntas: por que estou me comunicando? (qual é o objetivo preciso em minha mente, a função total do discurso); que informação já está à disposição do leitor? (isto é, que informação preciso ser fornecida para preencher claros); A quem estou me dirigindo? (qual é a relação entre o autor, leitor, que língua é apropriada a esta relação e ao conceito do autor sobre os elementos, que conhecimentos comuns existem e que presuposições podem ser feitas sobre o leitor); como posso expressar melhor a mensagem em termos formais? (isto é, relacionado com a estrutura textual, há conceitos de coerência e coesão).

Sem dúvida parte da resposta à primeira pergunta será relacionada ao modo com que aquele que escreve deseja ser percebido, seria humorístico, persuasiva ou autoritariamente.

A área de "análise de registro" nos tem dado uma variedade de categorias para definir as razões para a escolha de linguagem, relacionadas às três últimas perguntas. Um trabalho pioneiro foi executado por $\mathrm{Joos}^{38}$, que postulou cinco estilos lingüísticos que variam de acordo com o tópico, explicidade, grau de participação do falante/ouvinte, o estado relativo de premeditação dos participantes e o grau de pressuposições compartilhadas. Considerações das dimensões de Joos podem dar uma compreensão extra das diferenças entre linguagem falada e escrta pois seus cinco estilos correlacionam com a distância entre o falante/ouvinte. De um lado do seu espectro está o seu estilo "congelado" equivalente à Língua escrita, um tipo de "prosa falada".

A percepção do escritor sobre sua audiência (pergunta três acima)

TJAKOBSON, p. 350.

30 JOOS, p. 6. 
isto é, sua idade, seu status, o que conhece ou sobre o que está interessado afetará o tratamento que o escritor dá ao assunto escolhido. Crystal e Davy ${ }^{39}$, distinguiram oito dimensões para definir as características lingüísticas de diferentes registros em inglês, aos quais eles se referem como dimensões dos limites situacionais. Elas são: dialeto, tempo, discurso, área, status, modalidade e singularidade ("individuality, dialect, time, discourse, province, status, modality and singularity" ". O trabalho destes autores oferece pontos de partida para o lingüísta mas sofre pelo fato de que suas "provinces" (áreas) foram tomadas em sentido muito amplo (isto é, a linguagem da religião, por exemplo, ${ }^{40}$ ). A análise destes autores foi também principalmente num nível formal, de consideração do significado dos elementos lingüísticos, mas do que propriamente o reconhecimento do seu valor em comunicação retórica. É algo surpreendente que eles tenham negligenciado totalmente a área da linguagem científica que, em suas formas escritas, tem um conjunto de fórmulas ou convenções comparativamente rígido. Freqüentemente a prosa será da seguinte forma: um abstrato (sinópse), uma introdução, uma razão, metodologia, apresentação, resultados, discussão de resultados, conclusão, Isto não é necessariamente a seqüência de estudos científicos experimentais mas é um formato adotado frequentemente por escritores para facilitar a predictabilidade entre sua "audiência". . . Como Smith ${ }^{41}$ já disse "effective writing is writing that meets the conventional demands of the texts, demands that impose themselves on both writers and readers".

Desta forma, além dos interesses do leitor e seu prévio entendimento do tópico, suas presuposições, certas normas, o respeito por convenções, têm que ocorrer para a comunicação ser eficiente.

O texto poderá assim ser visto como um pivô entre o escritor e o leitor, mas pode se tornar uma barreira, e uma fonte também em termos de preencher os claros da informação. $O$ texto por vezes opera como um espelho de dois lados refletindo os pensamentos de ambas as mentes. Cada um deles depende do outro; o leitor depende das convenções empregadas pelo escritor e elaboradas nas expectativas e predições sobre sua audiência. Compreensão perfeita, (i. é, . . ." when the writer 's intentions and the reader's expectations coincide completely", 42 nunca pode ocorrer pois, como Popper ${ }^{43}$ já observou, o significado depende do contexto do qual é tirado e contextos sempre mudam. O texto está

${ }^{39}$ CRYSTAL \& DAVY, p. 64.

"CRYSTAL \& DAVY, p. 175.

${ }^{41}$ SMITH, p. 80.

${ }^{4}$ SMITH, p. 73.

${ }^{43}$ POPPE R, K. R. Unonded quest: an intellectual autobiography. London, Fontana, 1976. p. 87. citado p. widdowson, 1980. 
fora das mãos do escritor conforme ele é lido e sua interpretação depende do estado corrente de conhecimento, expectativas e necessidades do receptor. As expectativas e convenções se dão em todo os niveis desde o global incluindo título, conteúdo, capítulo, sub-títulos e organização, eventos, parágrafos e a palavra. Na prosa científica, como já mencionamos acima, a termonologia e a estrutura do texto é apresentada de maneira que se atém às expectativas do leitor. A aprendizagem é, portanto, incidental, o resultado da compreensão.

\section{CONCLUSÕES}

Pode ser conveniente achar-se que a fala e a escrita não sejam variações livres mas sim dois sistemas independentes de comunicação apesar de interrelacionados, os quais compartilham da mesma gramática a um nivel abaixo do da superficie com caracteristicas lingüisticas e não lingüisticas próprias. "Written language reflects a linguistic analysis of categories (eg. sentence, letter) some of which are not related simply or directly to categories for spoken language". ${ }^{44}$ Por exemplo, enquanto na fala a unidade natural é a frase ou oração, às vezes atada de forma bem solta, a unidade natural da escrita é o parágrafo que deve consistir de sentenças bem atadas em termos de coesão, expressando um conjunto de funções retóricas lógicas. Esta é a razão pela qual a forma escrita é geralmente mais explícita, concisa e curta. Como é uma mostra de palavras no espaço e não no tempo como na fala, deve naturalmente referir-se ao espaço, isto é, a capítulos anteriores, páginas, parágrafos e sentenças, a idéias já mencionadas ("este" e "aquele". "acima" e "abaixo"), orações "parenthical". E também a razão pela qual "the skills needed for successful. . . writing are partly distinct from those needed for speaking. . . and the relevant linguistic patterns are also partly different" 45 .

A linguagem escrita tem que ser independente do contexto no qual foi produzida originalmente, pois o leitor está ausente à hora da produção. Por isso aquele que escreve tem que não só explorar os aspectos visuais da apresentação. A acuracidade da escolha da língua escrita é essencial pois aquele que recebe a mensagem é muito menos tolerante a desvios. Assim a escrita é um código elaborado de convenções, uma entidade, muito diferente da linguagem falada que varia consideravelmente de falante para falante e de situação para situação. As ambiguidades têm que ser evitadas através de referências explicitas pois as caracteristicas de superficie sozinhas carregam as nuances de

44 HUDSON, R. Some issues on which linguists can agree. Journal of Linguistics (17): 340. 1981 .

${ }^{45}$ HUDSON, p. 341. 
significado. A escrita é portanto, uma sequência muito cuidadosa de pensamenios, e uma classificação precisa de idéias espressando objetivos específicos e limitados. Então é claro que "writing is much more than an orthographic symbolization of speech. It is purposeful selection and organization of experience". ${ }^{46}$ A estrutura textual tem que ser um conjunto de sentenças interligadas por uma complexa rede de referências, como as dos sistemas de artigos e pronomes.

Entretanto, a mensagem transmitida será dirente daquela da fala, não somente pelos elementos de coesão gramatical e léxica mas também pelos elementos que indicam funções comunicativas. Estas funções e estrutura retórica encontrada ao nível das funções individuais. Para aquele que analisa o discurso, a escrita é essencialmente uma negociação interativa de significado pela qual o que é apresentado na página impressa como texto escrito tem que ser convertido em funções do discurso. Esta interação cria estruturas hierárquicas e combinações de proposições que levam a unidades maiores de comunicação. Há assim dois aspectos para o estudo da relevància da escrita. O primeiro se refere a tipos de sentenças ou atos comunicativos em isolamento isto é, como uma única sentença funcional como uma mensagem. A necessidade é especificar as condições pelas quais uma certa forma lingüistica atua como um certo tipo de oração e a relação que estabelece classes de atos comunicativos. A segunda área de estudo tem a ver com o modo pelo qual as frases se unem com outras frases para desenvolverem unidades maiores de comunicação: a coerência de orações em seqüência.

$O$ discurso escrito está longe de ser um fenômeno simples. A forma e a função se interligam, as partes diferentes são intricadamente relacionadas já que a mensagem mostra significado em vários e diferentes niveis. Estes incluem as categorias semânticas básicas de classes de pala. vras e estruturas, relações sintáticas hierárquicas e estrutura textual de função retórica e coerência do discurso. Estes significados existem simultaneamente mas podem ser descrito a cada nível.

Dai, a mensagem transmitida por um trecho do discurso "is a complex product of all individual statements, the order in which they are presented, the relationship, explicit or implicit, holding between them, and the way particular statements are grouped into paragraphs.47

\footnotetext{
4ARAPOFF, W. Writing: a thinking process. English Language Teaching Forum, 8 (3): 233-40, nov. 1970.

${ }^{47}$ WIDDOWSON, H. G. The communicative approach and its applications. In: BRITISH COUNCIL. English for Specific Purposes; an International Seminar, Paipa, Columbia, London, 1977. p. 21.

- para uma leitura mais detalhada ver Litowitz, B. E. "Writing from a developmental perspec tive". Chicago, 1978. Northwestern University. Mimeografado.
} 


\section{POST SCRIPTUM}

Ao escrever este estudo, o autor encontrou quatro vantagens da linguagem escrita:

1. como um elemento para a melhor retenção de fatos.

2. como uma fonte permanente para referência futura.

3. como um meio de classificar idéias.

4. como uma evidência física da realização.

O formato abaixo de quatro sinótico poderia ser uma maneira clara de se resumir as principais diferenças entre escrita e fala (ao mesmo tempo que ilustra a vantagem da distribuição na forma gráfica).

Escrita

1. A qualidade abstrata é intensificada pelo deslocamento no termo

2. Se torna um registro permanente do acontecimento, um artefato documentário da história.

3. O formato visual é de convenção, etiqueta, de acordo com etilo, registro e função.

4. Tende ao formal e conservador; menos inclinado a mudar.

5. $O$ que recebe a mensagem está ausente.

6. Não recíproca, nenhuma resposta imediata.

7. O escritor tem duplo papel; o leitor é uma presença psicológica.

8. O receptor é um leitor; ler requer esforço.

9. Conhecimento pressuposto. Tem que se fazer explícito.
Fala

1. E tempo real-"agora"

2. Vern e vai; e efêmera e transitória.

3. E não visual (exceto com espectógrafos)

4. Inclui modas, coloquialismos, gíria.

5. O que recebe a mensagem está presente, usa uma varieda. de de características paralingüísticas como "feedback".

6. consciência constante de uma "audiência".

7. Papel 'simples' em interação face a face.

8. O receptor é um ouvinte; menor esforço necessário.

9. De um certo modo. Não necessário - pode ser verificado concomitantemente. 
10. Redundância de natureza sintática - semântica deliberadamente adicionada com finalidade de clarificação.

11. E possivel a monitoração parar, reler, riscar, reescrever.

12. Ritmo vagaroso

13. Convenções de Sintaxe, ortografia, coesão e coerência.
10. Repetição, refraseamento, pausas, marcadores de atenção.

11. monitoração através do "feedback" da audiência.

12. ritmo variado

13. menos controlada, produção oral e desenvolvimento simultâneos.

\section{ABSTRACT}

This short paper is an attempt to provide the postgraduate student with an overview of linguistic definitions of written language, to define writing, as it were, in its own right. Thus it includes discussion of written language as a substance, with writing as an operation and with the acquisition of written forms; finally there are sections on the way writing functions as communication and the writer's awareness of audience i. e. writing from a socio-linguistic standpoint.

\section{REFERÊNCIAS BIBLIOGRÁFICAS}

1 ABERCROMBIE, D. Elements of general phonetics. 3. ed. Edinburgh, Edinburgh University Press, 1971.

2 ARAPOFF, W. Writing: a thinking process. English Language Teaching Forum, 8 (3) : 233-40.

3 BERNSTEIN, B. Social structure, language and learning. Educational Research (3) : $163-76,1971$.

4 BLOOMFIELD, L. \& BARNHARDT, C. L. Let's read: a linguistic approach. Detroit, Wiley, 1961.

5 BOLINGER, D. Aspects of language. 2. ed. New York, Harcourt, Brace, Jovanovich, 1975.

6 CLARK, R. Adult theories, child strategies and their implications for the language teacher. In: ALLEN, J. P. B. \& CORDER, S. P. The Edinburgh Course in Applied Linguistics. London, Oxford University Press, 1975.v. 2, p. 291-347.

7 CRYSTAL, D. \& DAVY, D. Investigating English style. London, Longman, 1969.

8 DAVIES, A. \& WIDDOWSON, H. G. Reading and writing. In: ALLEN, J.P.B. \& CORDER, S. P. The Edinburgh Course in Applied Linguistics. London, Oxford University Press, 1975. v. 3, chapter 6.

9 GINSBURG, $H$. \& OPPER, S. Piaget's theory of in tellectual development; an introduction. Englewood Cliffs, Prentice-Hall, 1969.

10 HALLIDAY, M. A. K. \& HASAN, R. Cohesion in English. London, Longman, 1976. 
11 HUDSON, R. Some issues on which linguists can agree. Journal of Linguistics (17):339-42, 1981.

12 HYMES, D. Toward ethnographies of communication: the analysis of communicative events. In: GIGLIOLI, P. P., ed. Language and Social Context. Harmondsworth, Penguin, 1972. p. 221-44.

13 JAKOBSON, R. Concluding statement: linguistics and poetics. In: SEBEOK, T. A. Style in language. Cambridge, Mass., MIT Press, 1971. p. 350-77.

14 JOOS, M. The five clocks. Wilmington, University of Indiana Press, 1962.

15 KRASHEN, S. D. Second language acquisition and second language learning. Oxford, Pergamon Press, 1981.

16 LURIA, A. R. Development of the directive function of speech. Word, 15:341. $52,1959$.

17 LYONS, J. Introduction to theoretical linguistics. 2. ed. Cambridge, Cambridge University Press, 1972.

18 MARKOVA, A. K. The teaching and mastery of languages. London, Croom Helm, 1979.

19 O'DONNELL, W. R. \& TODD, L. Variety in contemporary English. London, Allen \& Unwin, 1980.

20 POPPER, K. R. Objetive knowledge. Oxford, Clarendon Press, 1972.

21 - Unended quest; an intellectual autobiography. London, Fontana, 1976.

22 SACHS; L. et alii. A simple systematics for the organisation of turn-taking for conversation. Language, 50 (4): 17.26, 1974.

23 SCHEGLOFF, E. A. Notes in conversation practice: formulating place. In: G1GLIOLI, P. P., ed. Language and social context. Harmondsworth. Penguin, 1972. p. 95.135.

24 SMITH, F. Writing and the writer. London, Heineman, 1982.

25 URE, J. Lexical density and register differentiation. In: TRIM, J. M. L., ed. Applications of linguistics: selected papers on the Second International Congress of Applied Linguistics. London, Cambridge University Press, 1971. p.

26 VYGOTSKY, L. S. Thought and language. New York, Wiley, 1962.

27 WEINREICH, U. Languages in contact. 4. ed. The Hague, Mouton, 1966.

28 WIDDOWSON, H. G. The communicative approach and its applications. In: BRITISH COUNCIL. English for Specific Purposes; an International Seminar. Paipa, Columbia. London, 1977.

29 - Language and communication. Edinburgh, 1973. Mimeografado.

30. - . "New Staets and Different kinds of Fdilure". London, 1980, Mimeogra. fado.

AGRADECIMENTO:

Agradeço a minha esposa pela tradução para portuguès. 